\title{
TENDÊNCIA DE COBERTURA E USO DO SOLO PARA A BACIA DE SEPETIBA: NOVOS ELEMENTOS PARA O PLANEJAMENTO AMBIENTAL E A GESTÃO DO TERRITÓRIO
}

\author{
TREND OF COVERING AND USE OF SOIL FOR THE SEPETIBA BASIN: NEW ELEMENTS FOR ENVIRONMENTAL \\ PLANNING AND MANAGEMENT OF THE TERRITORY
}

\section{RESUMO}

O tempo é uma das categorias fundamentais para a Geografia, afinal é a partir dele que se compreendem os processos de organização do território, bem como dos problemas ambientais, portanto, elemento peremptório para a gestão do território e o planejamento ambiental. O presente artigo tem como objetivo avaliar as mudanças de cobertura e uso do solo na bacia da Baía de Sepetiba, no município de Rio de Janeiro, oferecendo, a partir de uma metodologia baseada em um Sistema de Informação Geográfica Temporal (SIGT), uma perspectiva de análise que combina o tempo passado (2004), presente (2013) e futuro (tendencial). Através da metodologia aplicada foi possível constatar o intenso padrão de conversão de cobertura e uso do solo para a bacia, explicado, sobretudo, pelo desenvolvimento industrial, orientado pelo Programa de Aceleração do Crescimento (PAC), bem como, a ocupação residencial de classe baixa e média, sobretudo, em áreas suscetíveis a enchentes, inundações e deslizamentos, transparecendo os impactos de um ordenamento territorial orientado não pelo poder público, mas pelos agentes produtivos e dinâmica dos megaeventos.

Palavras-chave: Tempo. Produção do espaço. Zona Oeste. Modelagem de dados geográficos.

\begin{abstract}
Time is one of the fundamental categories for Geography, because through this concept, it is possible to understand the dynamics of spatial process, as well as to seek explanatory elements for the environmental problems, therefore, a peremptory element for the territory management and environmental planning. The objective of this paper is to evaluate changes in land cover and land use in the Sepetiba Bay basin, in the city of Rio de Janeiro, offering an analysis perspective based on a Temporal Geographic Information System (TGIS) which combines past (2004), present (2013) and future (trend) times. Through the applied methodology, it was possible to verify the intense pattern of land cover and land use conversion for the Basin, mainly explained by oriented industrial development, as well as the low and middle class residential occupation, especially in areas susceptible to floods and landslides, revealing the impacts of a territorial planning oriented not by the public power, but by productive agents and by mega-events that took place in the city
\end{abstract}

Keywords: Time. Production of space. West zone. Geographic data modeling.
Leandro Andrei Beser de Deus ${ }^{a}$

Antonio Carlos Oscar Júnior ${ }^{\text {a }}$

${ }^{\text {a }}$ Universidade do Estado do Rio de Janeiro (UERJ), Rio de Janeiro, RJ, Brasil

DOI: $10.12957 / g e o u e r j .2020 .37731$

Correpondência: leandrobeser@gmail.com

Recebido em: 5 out. 2018

Revisado em: 2 jun. 2020

Aceito em: 6 out.2020 


\section{A IMPORTÂNCIA DO ESPAÇO-TEMPO NA ANÁLISE GEOGRÁFICA DO AMBIENTE}

Conforme amplamente difundido por Santos (2004) e Santos (2008), alguns estudos necessitam do espaço e do tempo integrados para a realização de inferências sobre determinada problemática. Isso porque, conforme Almeida (1982), o comportamento dos seres humanos no espaço é resultado da interação entre as decisões tomadas em âmbitos diversos (político, econômico, cultural, sociológico, etc.), onde as decisões tomadas hoje, de alguma forma, estão relacionadas com um passado mais ou menos distante. Dada a complexidade crescente do espaço, criam-se, paulatinamente, linhas de continuidade que se entrecruzam em todos os sentidos, em que lugares pontuais de produção do espaço, bem como sua significação e ressignificação, não surgem todos ao mesmo tempo, se acumulam em diferentes momentos, a partir de eventos diversos, consubstanciando a malha de complexidade atual (ALMEIDA, 1975; SANTOS, 2008) e se refletindo, inexoravelmente, na qualidade ambiental.

Para a análise ambiental, interessa, pois, a compreensão desse acúmulo de eventos, marcado por decisões tomadas (sobretudo no âmbito político-econômico) em diferentes contextos temporais, afinal são elas que interferem ativamente na dinâmica do sistema territorial (OSCAR JÚNIOR, 2016). Conforme Gómez Orea (2007, p. 102): “EI sistema territorial es uma construcción social que representa el estilo de desarrollo de uma sociedad; se forma mediante las actividades que la población practica sobre el medio físico y de las interaciones entre ellas". No entanto, na Geografia ainda são poucos os trabalhos com perspectiva ambiental que desenvolvem um estudo espaço-tempo centrado na perspectiva do futuro, a partir da utilização de cenários ambientais, insumo fundamental para o desdobramento geográfico da gestão territorial e planejamento ambiental.

Dentro do fluxo temporal tradicional, podem ser destacados dois recortes, concretos ou não: o futuro e o passado. O futuro é a perspectiva primordial do planejamento ambiental e gestão territorial. O passado contribui com aprendizados para planejar o futuro. Se o planejamento implica decidir sobre ações futuras, previsões e estimativas são essenciais. No entanto, segundo Becker (1991, p.153), a história não se repete. Sendo assim, as ações futuras no planejamento não podem repetir o passado. Entretanto, pode-se aprender com as ações pretéritas, entender a dinâmica do passado, as tendências periodizadas com suas forças em escalas diferentes e compreender seus padrões impostos hoje, sendo causados e causadores. Assim, o que interessa é o modo como estes movimentos se entrelaçam, a sua interação e os seus pontos de ruptura.

É no âmbito da climatologia que tal recurso tem sido mais bem explorado, no entanto, seu potencial transcende essa área do conhecimento, permitindo, entre outras aplicações: avaliar os desdobramentos dos rumos políticos e econômicos, subsidiando a avaliação de políticas públicas ou, no momento em que estamos, do impacto das parcerias público-privadas nas reestruturações do espaço e do ambiente, seguindo os interesses externos ao local.

Nesse sentido, interessa também a complexidade da escala vertical fundada com a globalização, onde a ordem global tenta impor aos lugares uma única racionalidade, o que funda escalas superiores ou externas à escala do 
cotidiano (SANTOS 2008). Exemplo disso são os megaeventos que tiveram sede na cidade do Rio de Janeiro. Segundo levantamento realizado por Bare (2013), ao longo de quase uma década, entre 2007 e 2016, o Rio de Janeiro recebeu:

[...] quase um megaevento (esportivo ou não) por ano: Jogos Panamericanos de 2007, FifaFanFest de 2010, Rock in Rio de 2011, Rio+20 de 2012, Jornadas Mundiais da Juventude e Copa das Confederações ambas de 2013, Copa do Mundo de 2014, e finalmente as Olimpíadas de 2016 (BARE, 2013, p. 44)

Os megaeventos supramencionados, em especial os esportivos, promoveram uma reestruturação urbana e territorial no Rio de Janeiro orquestrada pela ordem econômica global, suplantando os interesses e múltiplas realidades do cotidiano e ratificando sua função de cidade mercadoria (LEVBRE, 1965). Para citar dois exemplos, destaca-se: a política de remoções forçadas (MACHADO-SILVA, 2010), bem como, a construção do campo de golfe olímpico em território da APA (Área de Proteção Ambiental) de Marapendi.

Tomando esse contexto carioca, com ênfase à Bacia da Baía de Sepetiba (Figura 1) que, segundo Gusmão (2010), nos últimos anos tem recebido:

Os impactos de uma agenda de investimentos que se apoiavam em dois pontos: (a) na ampliação da inserção da economia da região (e do país) nos fluxos de comércio internacional de commodities tais como minério de ferro, placas de aço e derivados de petróleo; e (b) na sua convergência em direção às infraestruturas portuárias situadas na baía de Sepetiba (GUSMÃO, 2010, p.26).

O presente artigo propõe a aplicação da metodologia desenvolvida por Beser de Deus (2013) para avaliação do cenário tendencial de cobertura e uso do solo em bacia hidrográfica urbana com intenso dinamismo econômico.

Figura 1. Mapa de Localização da Bacia Hidrográfica da Baía de Sepetiba (RJ).

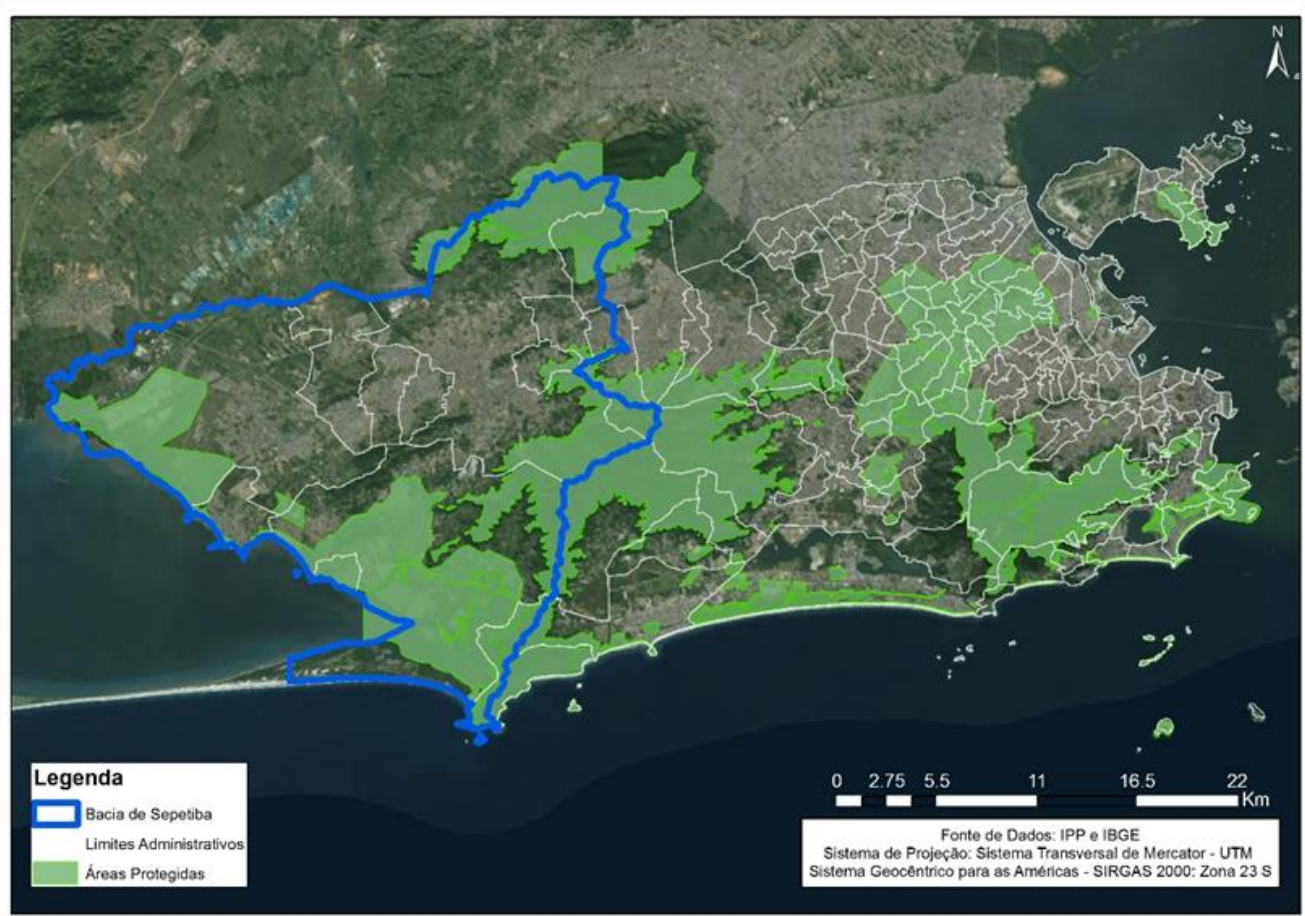

Fonte: Elaboração própria. 
A questão de mudanças nos padrões de cobertura e uso do solo tem despertado interesse, dentro e fora do meio científico, devido ao acelerado processo de mudança das últimas décadas e aos possíveis desdobramentos ambientais e socioeconômicos dessas mudanças, causando preocupações desde o nível local até o global. Segundo dados do Primeiro Inventário de Gases de Efeito Estufa no Brasil, realizado em 2011, entre os anos de 1990 a 2008, observou-se que 60,6\% das emissões de gases estufa advinham da UTMUTF Uso da Terra, Mudança do Uso da Terra e Florestas.

A proposta de Beser de Deus (2013) busca a junção de duas abordagens complementares, quantitativa e qualitativa, para construção de cenas a partir de técnicas digitais e analógicas fornecidas pelo aparato das Geotecnologias, auxiliadas por aspectos históricos ambientais que alicerça o estabelecimento de narrativas para formulação de cenários espacializados. Trata-se de uma perspectiva metodológica que visa responder às indagações de Câmara (2001): como capturar e representar computacionalmente a interação dinâmica entre espaço-tempo? Epistemologica e metodologicamente, trata-se da compreensão dialética entre aceleraçãodesaceleração, no tempo, e ampliação-redução, no espaço.

Fundamentalmente, o meio de organização e análise é representado por um Sistema de Informação Geográfica Temporal (SIGT), tecnologia de análise dinâmica do espaço e de sua configuração. Em softwares de SIG hoje, estão implementadas possibilidades de ferramentas computacionais de reconstituição do passado, análises espaciais do presente e funcionalidades para previsões futuras, baseadas em técnicas markovianas e de redes neurais artificiais (com base em heurística).

Trata-se de uma metodologia com extenso potencial para aplicação nos estudos sobre mudanças de cobertura e uso do solo, permitindo a realização de análises mais coerentes com a categoria espaço-tempo, já que essa problemática trata de questões de transformações de estado. Como se espera, as diferentes abordagens serão trabalhadas conjuntamente para enriquecer o estudo. Depois da integração proposta, será possível preencher algumas lacunas pretéritas e subsidiar a elaboração de modelos preditivos sobre variadas questões espaço-temporais.

\section{MARCO TEÓRICO}

Especificamente sobre o marco teórico, em IBGE (2006) há várias definições e conceitos consagrados além da avalanche de termos novos, associados com as interpretações de padrões de cobertura e uso do solo e da terra em diferentes regiões e níveis de detalhe. Com a melhoria técnica e tecnológica, sobretudo na qualidade e diversidade de imagens orbitais, houve aumento exponencial de trabalhos acadêmicos sobre este objeto, entretanto, para este artigo serão considerados aqueles que permitem uma melhor compreensão do 
estado da arte sobre a abordagem teórico-metodológica desenvolvida em relação às mudanças de cobertura e uso do solo ou terra.

\title{
COBERTURA E USO DO SOLO
}

Dada a importância do tema, hoje, ele é considerado parte fundamental de uma ciência aplicada intitulada ciência de mudanças da terra/solo (ELLIS, 2012) que utiliza fundamentalmente técnicas de sensoriamento remoto como ferramenta de análise. Atualmente, há debates em relação ao conceito, sobretudo em relação à aplicação de solo e terra.

Segundo FAO (1976), o termo terra foi definido como:

\begin{abstract}
o segmento da superfície do globo terrestre definido no espaço e reconhecido em função de características e propriedades compreendidas pelos atributos da biosfera, que sejam razoavelmente estáveis ou ciclicamente previsíveis, incluindo aquelas de atmosfera, solo, substrato geológico, hidrologia e resultado da atividade do homem, de acordo com a FAO" (FAO, 1976, p. 60).
\end{abstract}

Para oferecer alguma explicação e diferenciação, considera-se que o termo terra tem melhor aderência para as escalas regional e global. Já o termo solo, também muito comum, é mais adequado para aplicações próprias da escala local e, principalmente, espaços urbanos. Contudo, nem sempre essa distinção é respeitada nas diferentes publicações, algumas delas abordadas a seguir, gerando uma confusão contraproducente diante de uma perspectiva polissêmica.

Outro termo caro a essa ciência é o de mudança, caracterizado como algo que: altera alguma coisa ao longo do tempo; tem uma direção, ritmo de alteração e trajetória; é causada por alguma coisa; pode gerar deslocamentos e resultar no desenvolvimento de algo novo; pode ter impactos positivos e negativos no curto prazo; possui consequências no longo prazo; apresenta problemas, ameaças e oportunidades; frequentemente progressiva; a quantidade de mudanças acelera na medida em que a base de conhecimento da sociedade avança; possui um caminho voltado para o futuro e pode ser identificada e pesquisada (KILIAN, 2009).

Quando há modificação na cobertura e uso, ocorrem, em termos de cobertura, mudanças estruturais e funcionais nos sistemas causadas por fenômenos naturais e ações humanas, como alterações na biomassa e na produtividade da vegetação. Já modificações em termos de uso desencadeiam intensificação ou mudanças nos seus atributos do sistema, por exemplo, em sistemas agrícolas como a ocorrência de intensificação, extensificação, marginalização e abandono (ALVES et al., 2002).

O termo mudança de uso do solo, para Briassoulis (2000), significa transformações quantitativas na área (aumento ou diminuição) de um dado tipo de uso. Segundo a autora, a mudança de uso pode envolver sua 
conversão para outro, ou ainda a modificação de certo tipo de uso no seu padrão de desenvolvimento do mesmo uso e, assim, modificar-se em um sistema formador da paisagem (BENEDETTI, 2010). O mesmo pode ser entendido para cobertura: há mudanças quantitativas (internas) e qualitativas entre categorias e classes.

A título de exemplo, de acordo com Turner e Meyer (1994), uma mesma cobertura pode corresponder a diferentes usos (floresta usada para extração de madeira e recreação). No geral, um sistema de uso corresponde a uma cobertura, mas pode combinar a manutenção de mais do que um sistema agrícola combinando culturas e pastagens melhoradas; mudanças no uso normalmente acarretam mudanças na cobertura, mas podem ocorrer modificações na cobertura sem que isto signifique alterações no seu uso (BRIASSOULIS, 2000; AGUIAR, 2003).

Pode-se dizer, a partir de âmbito causal, que as mudanças de cobertura objetivam a inserção de usos imediatos ou futuros. Assim, é difícil dissociar os termos uso e cobertura que, na prática, estão essencialmente associados. Nesse artigo em especial, a maioria das nomenclaturas usadas para mapeamento ou estatísticas relacionadas ao espaço utiliza terminologias de mudanças de uso dirigidas para a dinâmica das atividades humanas e de cobertura para a presença ou não de elementos da natureza sobre a superfície.

Para estudos de dinâmica de cobertura e uso do solo, por exemplo, IBGE (2013) propôs, de forma genérica, as seguintes classes: Uso Agrícola, Uso Urbano, Usos da Água e Cobertura Florestal. Para a dinâmica da cobertura do solo, algumas classes podem ser agrupadas e, de maneira dicotômica e dinâmica, podem ser citados dois tipos de uso e cobertura conflitantes, usualmente, estudados ao longo do tempo: Uso Urbano e Não Urbano.

Deve-se salientar que estudos de mudanças de cobertura e uso do solo precisam levar em consideração a associação entre espaço e tempo, conforme sugere Santos (2004). Nesse sentido, é fundamental o recurso da periodização, afinal os contextos (temporalidades) dentro dos quais as mudanças estão inseridas são fundamentais para o entendimento sobre as diferentes formas de produção social que acontecem de forma diferente de acordo com o momento histórico.

\section{IMPLICAÇÕES AMBIENTAIS DA COBERTURA E USO DO SOLO}

Mudanças de cobertura e uso do solo podem gerar variadas implicações ambientais. Entende-se que essas mudanças são práticas antigas, afinal desde os primórdios, com a queima de áreas para facilitar a caça, passando pelo nascimento e modernização da agricultura e pela urbanização e metropolização do espaço, há uma aceleração e intensificação das mudanças ambientais, fruto de elevado grau de mudança de cobertura e uso. 
Com o intuito de garantir, nem sempre recursos essenciais, essas práticas geram consequências direta e indireta e inúmeros conflitos ambientais. Mais recentemente, a industrialização estimulou a concentração das populações humanas nas áreas urbanas (urbanização), acompanhados pela intensificação da agricultura nas terras mais produtivas e o abandono de terras marginais (ELLIS, 2012).

Tais processos reforçam a noção de conflito ambiental que vem sendo pensada sob uma perspectiva que o identifica como lutas sociais estabelecidas em torno de recursos naturais constituídos numa mesma base espacial de poder (OLIVEIRA, 2004) que ganha visibilidade em diferentes escalas. Sendo assim, a questão de mudanças nos padrões de uso e cobertura do solo tem despertado interesse devido ao intenso processo de mudança das últimas décadas e aos possíveis impactos ambientais e socioeconômicos dessas mudanças, que causam preocupações desde o nível local até o global (AGUIAR, 2003; ELLIS, 2012).

Especificamente no presente artigo, se destaca o nível local, e podem ser citados os problemas de erosão, sedimentação, contaminação, extinção de espécies e alterações do clima urbano. Em termos socioeconômicos, as mudanças de uso do solo afetam as estruturas de emprego, produtividade da terra, qualidade de vida, entre outros. Em áreas urbanas, causa preocupação, inclusive nos países hegemônicos, a expansão dos subúrbios e áreas industriais nas periferias das grandes cidades, causando perda de áreas para agricultura e de vegetação natural; e, finalmente, nos países não hegemônicos, as precárias condições de vida e ambientais resultantes do rápido crescimento de centros urbanos, principalmente em relação ao saneamento.

Um aspecto importante é que, embora sejam principalmente os impactos negativos que motivem o interesse pelo entendimento dos processos de mudança no uso e cobertura do solo, nem sempre as mudanças são negativas, especialmente se consideradas as escalas temporal e espacial de observação do evento e suas consequências, incluindo a possibilidade de adoção de medidas mitigadoras ou de adaptação. Contudo, mais do que negativo ou positivo, a questão mais importante que se coloca atualmente é a sustentabilidade do desenvolvimento, e o balanço adequado entre as questões sociais, econômicas e ambientais envolvidas (BRIASSOULIS, 2000; AGUIAR, 2003; SANTOS, 2004).

\section{A BACIA HIDROGRÁFICA DA BAÍA DE SEPETIBA}

O contraste marcante do sítio da cidade do Rio de Janeiro, formado entre o urbano e o natural, criou paisagens singulares. Essa peculiaridade fez com que a cidade do Rio de Janeiro seja, até hoje, considerada uma das mais belas do mundo, o que levou, inclusive, ao Ministério do Meio Ambiente (MMA) e ao Instituto do Patrimônio Histórico e Artístico Nacional (IPHAN) a prepararem um dossiê para a candidatura do Rio de Janeiro a Patrimônio Mundial, na categoria Paisagem Cultural, na Organização das Nações Unidas para a 
Educação, a Ciência e a Cultura (UNESCO), através dos seus assessores, o Conselho Internacional de Monumentos e Sítios (ICOMOS) e a União Internacional para a Conservação da Natureza (IUCN) (BATISTA, 2009).

Por outro lado, uma característica ambiental degradante na cidade é a poluição dos recursos hídricos. De acordo com a extinta Fundação Estadual de Engenharia do Meio Ambiente - FEEMA (2006) a cidade do Rio de Janeiro apresenta três macrobacias hidrográficas costeiras: a Bacia da Baía de Guanabara, a Bacia das Lagoas Oceânicas (atualmente, dividida em Bacia da Zona Sul e Bacia de Jacarepaguá) e a Bacia da Baía de Sepetiba. Todas as bacias possuem problemas críticos da poluição de suas águas, principalmente pelo despejo de esgoto sanitário in natura e também com a contaminação por substâncias tóxicas e metais pesados provenientes do despejo industrial histórico e irregular (INEA, 2006).

Especialmente sobre a bacia hidrográfica da Baía de Sepetiba, destaca-se o bairro de Sepetiba que em 2010 apresentava 56.575 habitantes (IBGE, 2010) e uma área urbanizada de 94,88\% (IPP, 2010), valores seguramente ampliados após uma década. Em Sepetiba, no ano de 2000, 26,78\% dos domićlios tinham acesso à rede geral de esgoto, já em 2010 esse percentual foi ampliado para 69,1\%.

Os dados de acesso à rede de esgoto refletem uma transição recente na característica de produção do espaço carioca. Os dados referentes ao ano 2000 retratam a prática de até então, com maior atuação, investimento e atenção às demandas da população que ocupa as áreas nobres da cidade (ABREU, 2006), sendo a partir do final do século XIX, as áreas próximas ao mar e que apresentavam potencial turístico e imobiliário, como os bairros da Zona Sul da cidade. Já os dados de 2010 demonstram o impacto dos investimentos estruturantes do PAC e dos megaeventos na infraestrutura urbana da cidade, promovendo uma reestruturação de todo o espaço urbano da cidade do Rio de Janeiro, com vistas à reprodução do capital, sobretudo do financeiro-imobiliário.

Nos anos recentes, a bacia hidrográfica da Baía de Sepetiba sofreu e vem sofrendo bastante com a pressão antrópica diante dos espaços urbanos por conta do crescimento no seu interior e ao seu redor e pelo desenvolvimento econômico, estimulado por órgãos das diferentes esferas de poder que viabilizou a consecução de empreendimentos como do Porto de Itaguaí, Arco Metropolitano, Companhia Siderúrgica Nacional, entre outros (ARAÚJO, 2007; GUSMÃO, 2010).

Grande parte dos empreendimentos instalados nesta região influenciou diretamente a organização socioespacial da população, pois algumas localidades de Sepetiba passaram a oferecer um número maior de bens e serviços, tornando-se espaços valorizados para o mercado imobiliário, que automaticamente passam a ser especulados, contribuindo para uma ampliação na ocupação das áreas de risco, sobretudo, pela população de baixa renda. 
A literatura aponta que essa população de baixa renda é a mais vulnerável aos riscos ambientais (VEYRET, 2007; NUNES, 2009; MENDONÇA, 2011). Não se trata de uma tautologia da pobreza, entretanto, devido o acesso diferenciado a oportunidades e capacidades, o extrato mais pobre da população torna-se mais vulnerável e, em muitas vezes, com conivência das políticas de ordenamento territorial promovidas pelo Estado (OSCAR JÚNIOR, 2014). Por isso, é urgente que as políticas pró-ativas (preparação e prevenção) sejam capitaneadas por um poder público orientado ao bem estar da população, tornando-se fundamental a análise de perspectivas do futuro, bem como, atentando para a participação da comunidade local, pois só assim, alcançaremos instrumentos técnico-científicos capazes de produzir conhecimentos necessários para a adoção de um planejamento territorial que seja socialmente justo, ecologicamente sustentável e economicamente viável (BRANDÃO, 2001, p.48).

\section{METODOLOGIA}

Tomando como ponto de partida o pressuposto inicial da necessidade de análise ambiental a partir da perspectiva tempo-espaço, a metodologia proposta baseia-se na construção e análises de modelos de tendência através da integração de técnicas e instrumentos quantitativos associados às análises.

De maneira geral, metodologias de Geoprocessamento, especificamente aquelas relacionadas aos Sistemas de Informações Geográficas são construídas considerando-se três níveis gerais de organização. 0 primeiro nível é o planejamento, que inclui a etapa de definição dos objetivos e objeto de estudo com sua abrangência, modelagem conceitual e levantamentos diversos. O segundo nível refere-se ao processamento, que abarca a entrada e o tratamento dos dados. E, por fim, o terceiro nível trata da análise, envolvendo consultas, saídas gráficas, testes, validação e armazenamento.

O caminho metodológico que se segue, de maneira resumida, é: retrospectiva, a partir do contexto atual, e perspectivas, a partir de tendenciais futuras. Os procedimentos técnico-operacionais utilizados para construção dos modelos de tendências e aspectos correlatos foram os seguintes: pacote de programas ArcGIS 10 (para estruturação ${ }^{1}$ do banco de dados espaço-temporal, construção das cenas do período atual, integração das camadas trabalhadas, análises espaço-temporais vetoriais e saídas gráficas) e funcionalidades do Idrisi (para construção das cenas e demais análises espaço-temporais matriciais).

Sobre o processo de escolha do simulador para modelagem de mudanças, inicialmente, foi elaborado levantamento dos simuladores disponíveis e de suas características básicas com o intuito de verificar qual deles melhor se ao objetivo do presente estudo. Entre os principais utilizados, destacam-se o simulador DINAMICA (SOARES-FILHO et al., 2005) e aqueles incluídos no software Idrisi. Como o escopo original era

1Processo de modelagem, implementação e operacionalização dos dados e informações. 
trabalhar com Cadeias de Markov e Redes Neurais Artificiais (RNAs), decidiu-se pela utilização dos simuladores do Idrisi, onde esses procedimentos estão disponíveis em módulos isolado e integrado.

Em seguida, dentro do ambiente Idrisi, dois módulos preditivos relevantes foram selecionados para novos testes operacionais: o CA_Markov (que inclui Autômatos Celulares e Cadeias de Markov, utilizando mapas de restrições a partir de caráter booleano e mapas de fatores por lógica fuzzy) e o LCM (Land Change Modeler for Ecological Sustainability com suporte em RNAs e Cadeias de Markov). Como decisão, optou-se pelo LCM. Os resultados gerados por esse módulo responderam de forma mais eficiente e apresentaram produtos diversificados e elucidativos, gráficos ou espacializados. Pode-se dizer que a principal vantagem do LCM, em comparação ao CA_Markov, é o seu potencial para modelar várias transições em diferentes modelos de previsão.

Para alimentar o modelo, foram utilizados dados de cobertura e uso do solo: 2004 e 2013 disponíveis no site Data.Rio do Instituto Pereira Passos (IPP). De acordo com Menezes (2005), um dos maiores desafios que esse tipo de pesquisa pode enfrentar, refere-se à criação de uma metodologia de compatibilização dos documentos cartográficos, por isso, após a aquisição, foi realizado tratamento dos dados:

1. compatibilização de sistemas de coordenadas, geodésicos e projetivos;

2. definição da resolução espacial (25 metros);

3. elaboração da matriz comparativa (1151 x 1345);

4. agrupamento das classes (por valores em grupo e agregados);

5. conversão entre sistemas (interoperabilidade) e entre estruturas de dados (vetor para raster);

6. processos algébricos entre matrizes para cruzamento das classes;

7. modelagem de mudanças de cobertura e uso do solo.

Os parâmetros para construção atenderam aos requisitos apresentados considerando T1 (2004) e T2 (2013) como marcos inicial e final para a modelagem de mudanças e T3 como modelo de previsão tendencial. A partir da metodologia supracitada é possível:

i. Análise de Mudanças: analisa as mudanças ocorridas na área, no intervalo, gerando gráfico de ganhos e perdas (em diferentes unidades) para as classes de interesse.

ii. Mapa de Tendência Cúbica: possibilita a identificação da direção na qual ocorre a maior mudança entre as classes de estudo. 
iii. Modelo de Deteç̧ão de Mudanças: apresenta as células que sofreram alterações de classe informacional no intervalo de análise.

É interessante observar que nesse artigo optou-se pela ênfase ao recorte da história recente, conhecido como a década dos megaeventos, conforme já mencionado anteriormente. Assim, justifica-se a escolha metodológica das cenas ambientais, que serviram de input para a modelagem: 2004 e 2013, dois anos, dentro do período, que abarcam as transformações mais intensas, notadamente relacionadas aos maiores eventos esportivos ocorridos na cidade.

\section{RESULTADOS: ANÁLISE MULTITEMPORAL E TENDÊNCIAS}

Apesar da importância das áreas naturais para o município, não só por seus serviços ecossistêmicos, mas também por fazer parte da imagem cultural da cidade, já em 2005 um estudo de indicadores e mapeamentos de uso e ocupação do solo realizado pela Secretaria de Meio Ambiente do Município do Rio de Janeiro (SMAC, 2005) apontavam para a evolução de sua degradação.

A partir da metodologia e da perspectiva analítica proposta, para a área de estudo, foi possível a identificação de dois processos que influenciam a pressão sobre as áreas naturais do município.

O primeiro processo refere-se ao crescimento urbano e econômico da bacia hidrográfica da Baía de Sepetiba que direciona e pressiona o Parque Estadual da Pedra Branca (PEPB). Esse processo, anteriormente apontado pela SMAC (2005), continua evidente nos resultados para o intervalo entre 2004 e 2013. A partir das Figuras 2, 3 e 4, se observa o contraste da redução das áreas não urbanizadas que coincidem com a expansão das áreas urbanas. Esse resultado indica a persistência desse processo, um reflexo da lógica de financeirização imobiliária que marca a atual urbanização da Zona Oeste do município do Rio de Janeiro.

Figura 2. Crescimento Urbano entre 2004 e 2013 na bacia hidrográfica da Baía de Sepetiba.

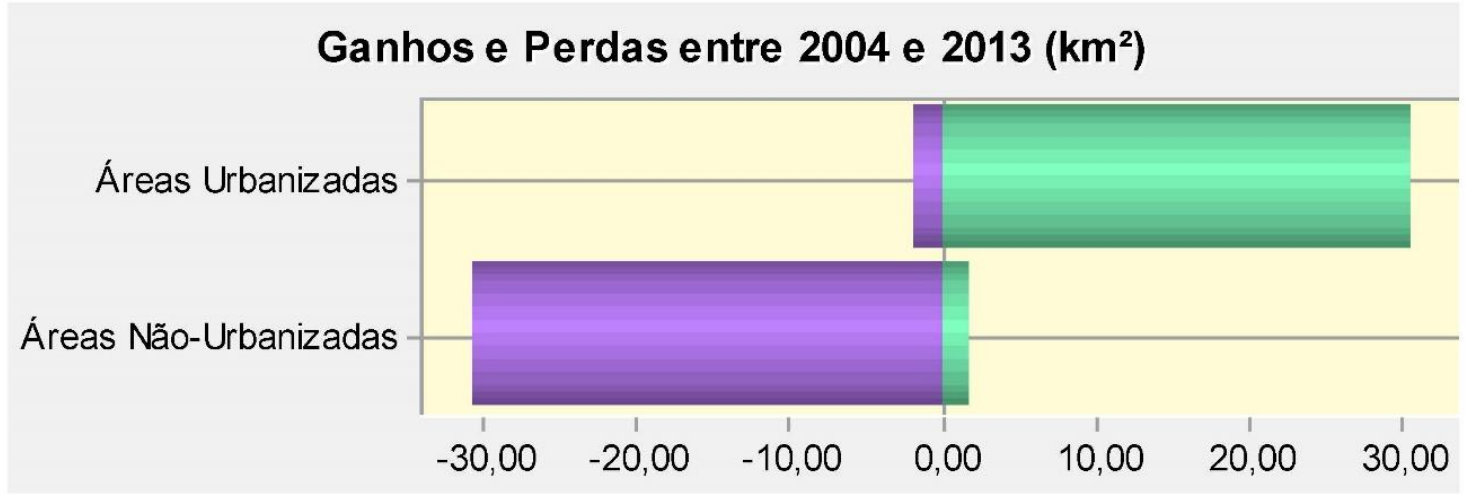

Fonte: Elaboração própria. 
Figura 3. Detecção de Mudanças de Uso do Solo na Bacia Hidrográfica da Baía de Sepetiba entre 2004 e 2013

\section{Mapa de Mudanças entre 2004 e 2013 da Bacia Hidrográfica da Baía de Sepetiba}



Fonte: Elaboração própria. 
Figura 4. Mapa de Tendência de Superfície Cúbica da Urbanização na Bacia Hidrográfica da Baía de Sepetiba.

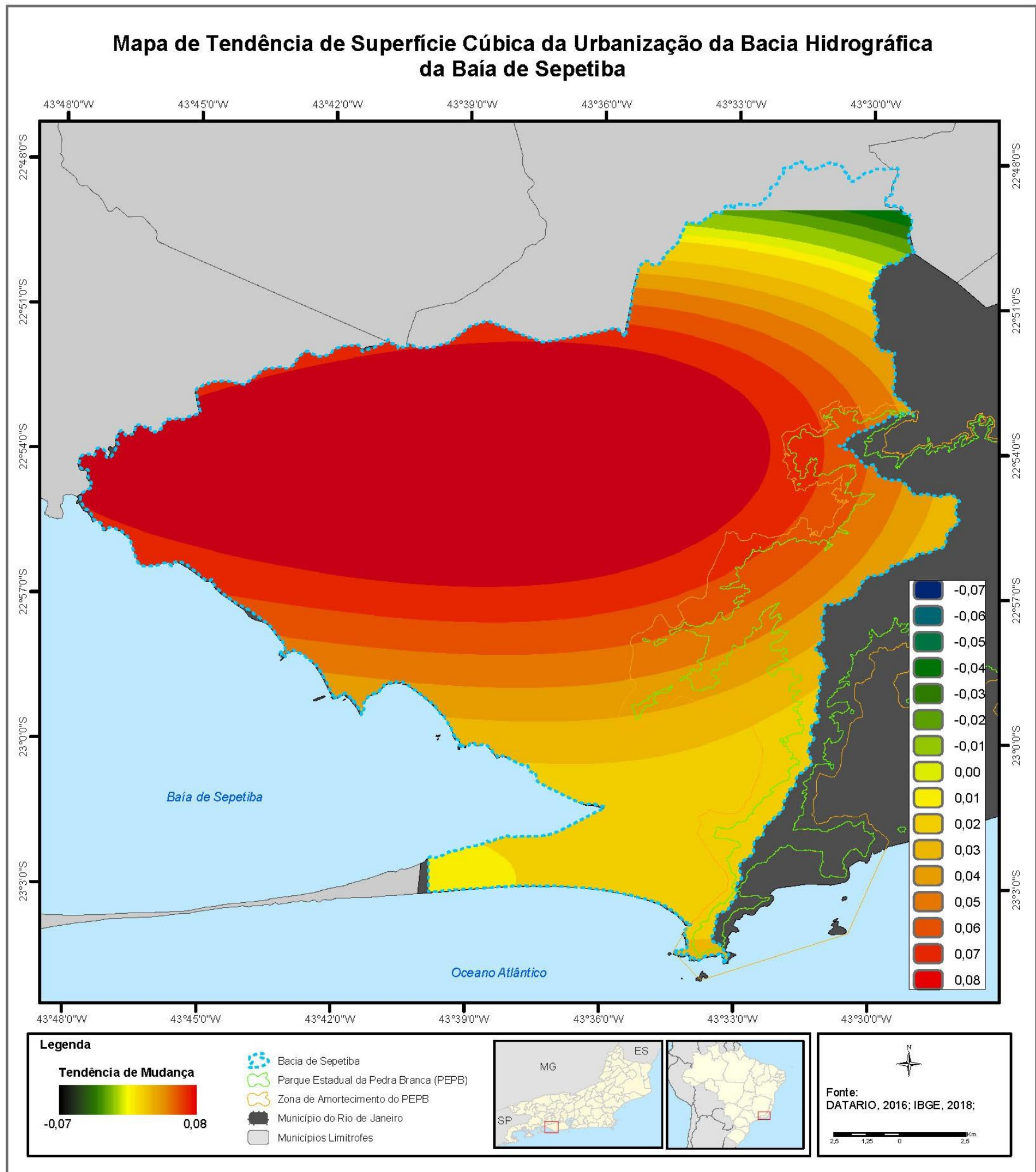

Fonte: Elaboração própria. 
Em relação à Figura 3, as transições observadas para a bacia da Baía de Sepetiba, no Rio de Janeiro, apontam que as mudanças de áreas não urbanizadas para áreas urbanizadas se concentram, mais significativamente, na porção norte-nordeste da bacia, área limítrofe com a Baixada Fluminense e vetor de crescimento urbano e industrial da cidade. Esse eixo evidencia um modelo de consolidação do desenvolvimento da periferia carioca, em que se reconfiguram novas centralidades dentro da metrópole em função do crescimento das atividades econômicas que produzem dinamismo nestes subcentros, como por exemplo, Campo Grande, capitaneados pelo avanço produtivo em função da cadeia do petróleo e do Porto de Itaguaí (ARAÚJO, 2007; GUSMÃO, 2010).

A tendência de conversão perde força em direção à porção sul-sudeste, tendo um desmatamento mais fragmentado em polígonos menores. A partir da Figura 4 é relevante mencionar o papel da zona de amortecimento do Parque Estadual da Pedra Branca, atuando como limitador do processo acentuado de conversão do uso do solo para o período em questão; entretanto, sofrendo pressão significativa pelo uso urbano.

De acordo com o Sistema Nacional de Unidades de Conservação - SNUC (2000), artigo 2aㅡ, as zonas de amortecimento referem-se ao entorno de uma unidade de conservação, onde as atividades humanas estão sujeitas a normas e restrições específicas, com o propósito de minimizar os impacos negativos sobre a unidade. Eis que, para a gestão territorial e planejamento ambiental, assume importância, não apenas os entraves territoriais protegidos (Unidades de Conservação), mas em termos de dinâmica da conversão do uso do solo, as próprias zonas de amortecimento.

O segundo processo que influencia a pressão sobre as áreas naturais do município refere-se à dinâmica (Figura 5) ou crescimento de áreas residenciais (Figura 6), de áreas não edificadas (Figura 7) e de áreas industriais (Figura 8) sobre áreas sujeitas à inundação (áreas úmidas e/ou brejosas). Trata-se de um processo impulsionado tanto pelo surgimento de loteamentos e condomínios irregulares, quanto pela ocupação por atividades industriais, cujo incremento foi significativo nessa bacia durante 2004 e 2013 . Essa situação é especialmente preocupante, pois além da perda de áreas naturais acarreta também à cidade sérios problemas relacionados à ocupação de áreas úmidas (impermeabilização do solo) e intensificação de ocorrências de desastres meteorológicos e geomorfológicos. 
Figura 5. Análise Multitemporal de Classes de Cobertura e Uso do Solo entre 2004 e 2013 na Bacia Hidrográfica da Baía de Sepetiba.

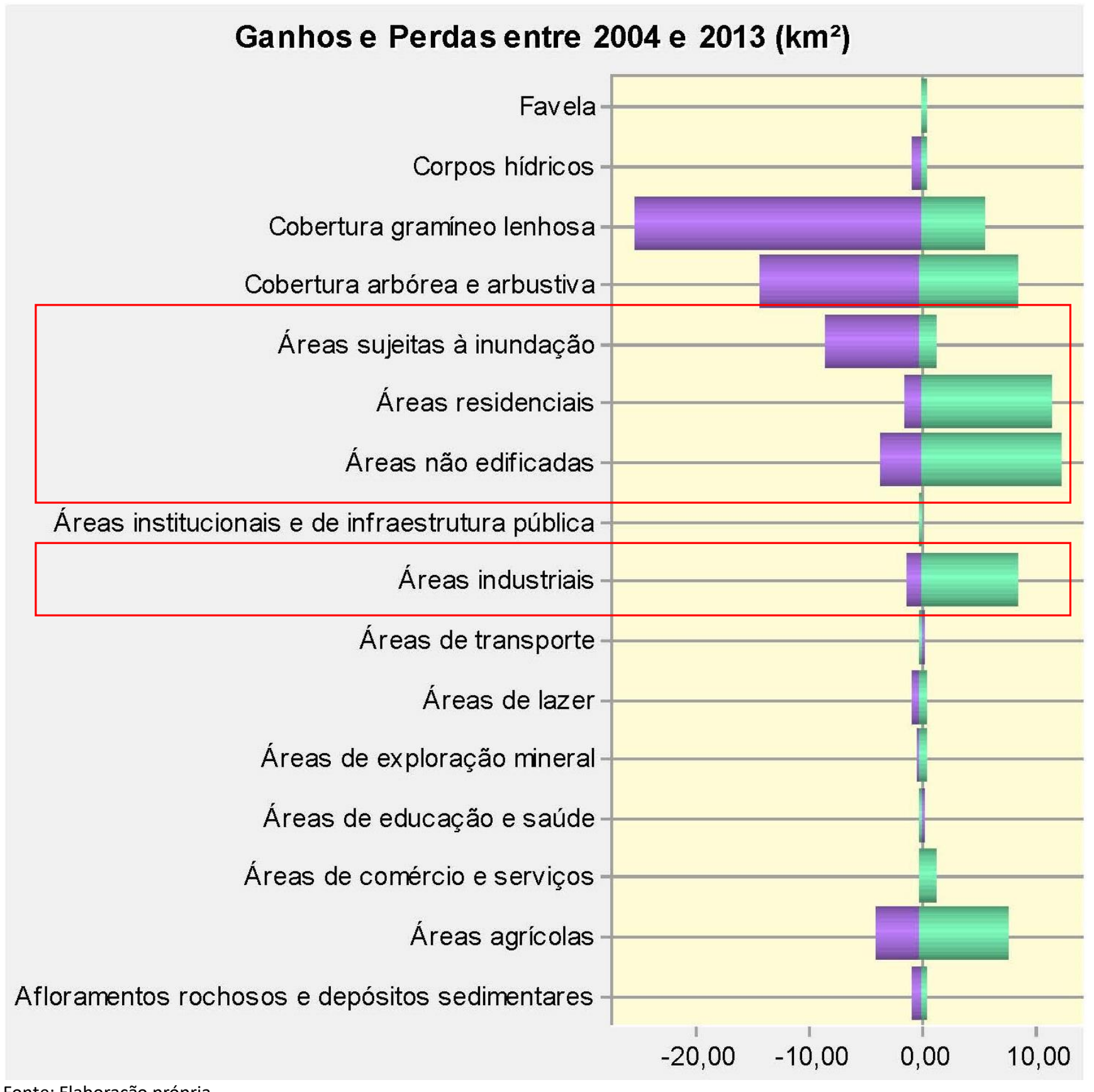

Fonte: Elaboração própria. 
Figura 6. Mapa de Tendência de Superfície Cúbica da Expansão das Áreas Residenciais na Bacia Hidrográfica da Baía de Sepetiba.

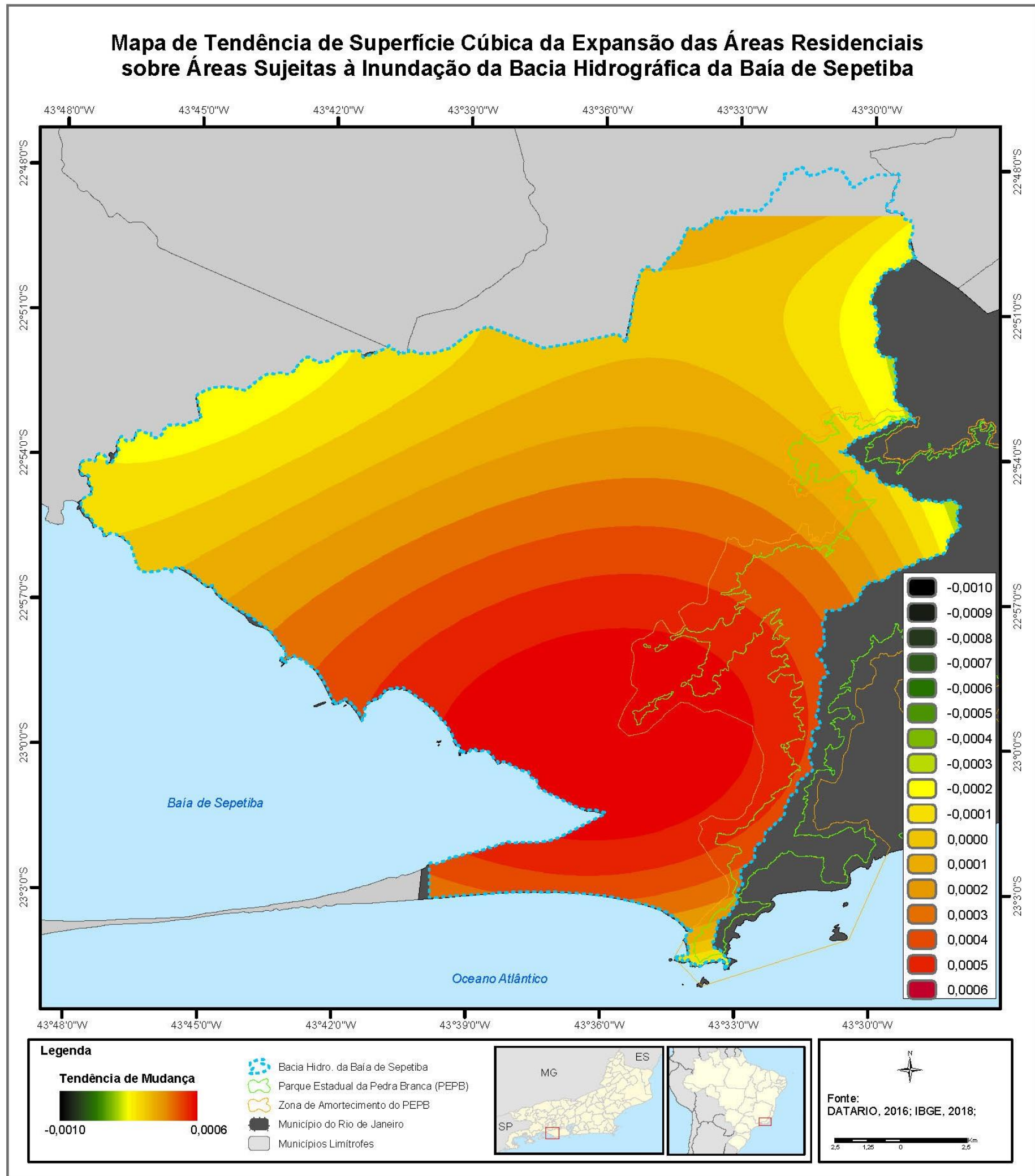

Fonte: Elaboração própria. 
Figura 7. Mapa de Tendência de Superfície Cúbica da Expansão das Áreas Não Edificadas na Bacia Hidrográfica de Sepetiba.

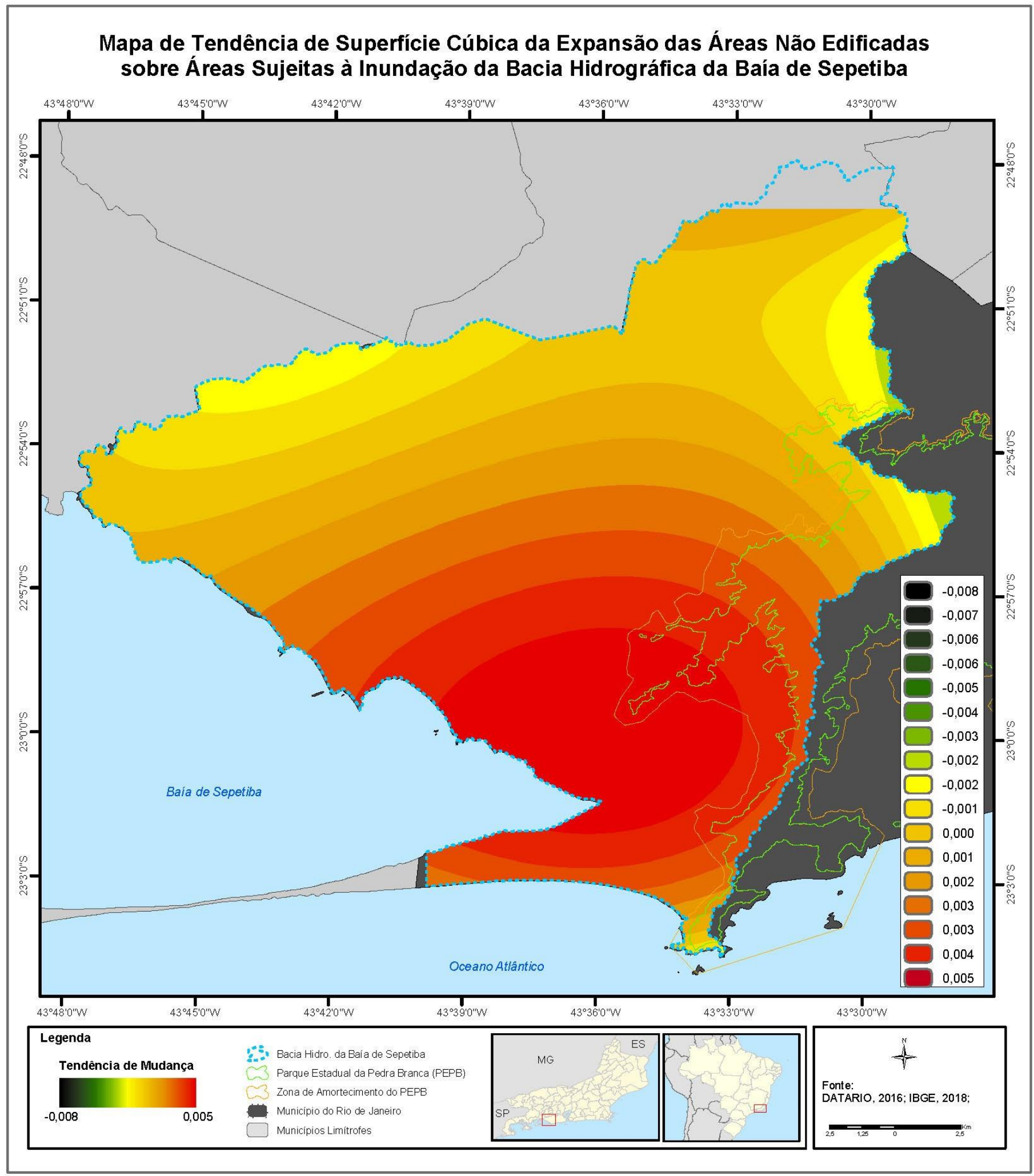

Fonte: Elaboração própria. 
Figura 8. Mapa de Tendência de Superfície Cúbica da Expansão das Áreas Industriais na Bacia Hidrográfica de Sepetiba.

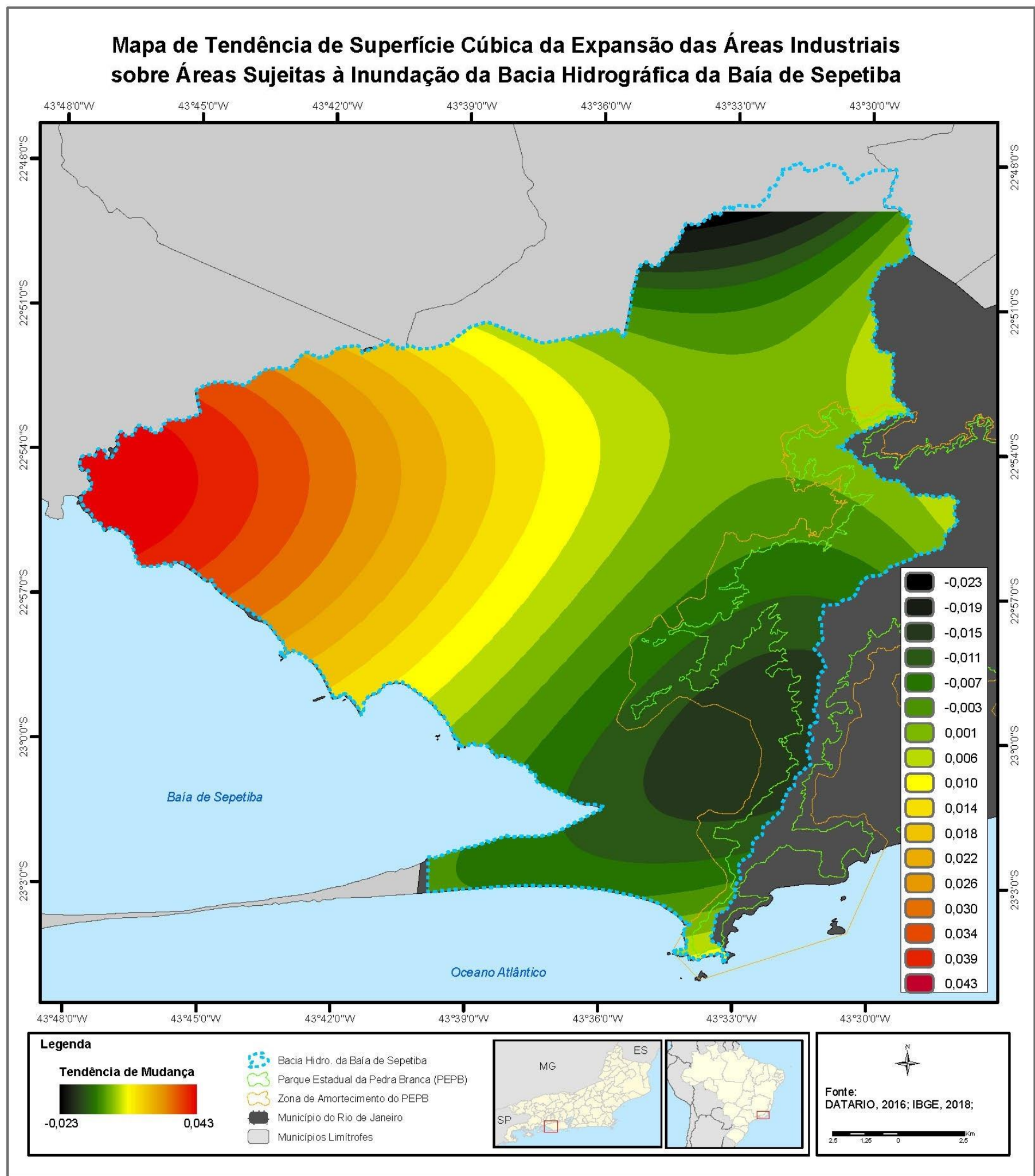

Fonte: Elaboração própria. 
Esses cenários também são agravados pela falta de uma visão coletiva e pactuada de planejamento do desenvolvimento e de uma política de uso e ocupação do solo na bacia. A diferença na distribuição da infraestrutura urbana, da oferta de serviços públicos, do acesso ao lazer e a cultura e da oferta de empregos também estão relacionados a essa lacuna de planejamento do desenvolvimento, reforçando a segregação e diferenciação socioespacial no ambiente da bacia, permitindo ao mesmo tempo a reprodução capitalista e a ampliação dos conflitos, dos riscos e da degradação ambiental.

Ambos os processos encontram-se alinhados com a periodização defendida por Gusmão (2010), em que, no intervalo temporal abordado pelo artigo, prevaleceram decisões conduzidas pelo setor produtivo, comandados pelo Programa de Aceleração do Crescimento - PAC, com dois eixos de intervenção: dragagem dos portos, duplicação da BR-101 e implantação do Arco Metropolitano, projetos que não inovam, pois estão alinhados a intervenções datadas de 1970; (ii) as ações voltadas para a agilização de processos administrativos vinculados à concessão de licenças e financiamentos para a execução dos projetos produtivos" (GUSMÃO, 2010: 15.).

Diante do exposto, ratificam-se as conclusões de Gusmão (2010) de que a área de estudo se encontra submetida a um conjunto de pressões de ordem econômica que intensificam o processo de modificação de cobertura do solo, reestruturando os espaços a partir de processos decisórios liderados por corporações privadas. Outrossim, materializa as considerações de Coelho (2009), acerca dos impactos ambientais urbanos, uma vez que se constata que não é o crescimento demográfico ou o ser humano, por natureza, o culpado por tais impactos, mas sim a estrutura de produção e reprodução socioespacial, sob auspícios de uma economia neoliberal que avança com o projeto capitalista de mercantilização do espaço.

\section{CONSIDERAÇÕES FINAIS}

Inicialmente, deve-se ressaltar que a literatura tem conduzido, recentemente, reflexões teóricas sobre os contextos de mudanças da cobertura e uso do solo e da terra, bem como a preocupação ambiental sofreu redirecionamento, de modo a privilegiar também as questões sociais, mostrando a tendência atual de orientação desses estudos, segundo o conceito de justiça ambiental (ACSELRAD et at., 2004).

A respeito do marco metodológico, é preciso entender como funcionam as mudanças a partir do pensamento sistêmico; destacam-se, eventos, padrões e estruturas, que precisam ser levados em consideração, permitindo o desvelar dos processos geográficos. Em seguida, a partir desse entendimento, aplicar tais princípios à modelagem e construção de cenários e modelos de cobertura e uso da terra.

Especificamente sobre o sítio urbano do Rio de Janeiro, pode-se dizer que este sofreu um processo histórico de exploração de suas áreas naturais e adensamento populacional que culminou em diversos problemas de 
vulnerabilidade e suscetibilidade, que são, em sua maioria, consequência da intensa ocupação das áreas de risco, oriunda do paulatino enfraquecimento e baixo poder de fiscalização do poder público sobre o território, expondo a população a alagamentos, inundações e deslizamentos de encostas.

Os conflitos ambientais provenientes das mudanças de cobertura e uso do solo devem ser compreendidos dentro dos diferentes contextos históricos, políticos e econômicos pelos quais atravessou a área em questão, que deve ser integrada em diferentes escalas. Entre elas, compreender que a Zona Oeste, onde a área de estudo se localiza, tem como marca um processo de ocupação territorial historicamente lento, relativamente recente, porém crescente. Sempre considerada área de reserva fundiária para expansão da cidade, ainda hoje é uma opção barata para população de baixa renda, coexistindo com: grandes áreas de proteção ambiental, presença forte de áreas militares, permanência de algumas áreas agrícolas e grandes distritos e zonas industriais (Santa Cruz, Palmares, Campo Grande).

Sendo assim, a Zona Oeste é uma importante região da Cidade do Rio de Janeiro, representando quase 50\% do território do município. Antiga área agrícola, que deixou passivo ambiental histórico relevante, principalmente como resultado do Ciclo do Café.

Entende-se que a gestão ambiental não pode ser apreendida em sua totalidade fora do contexto processual da organização do espaço, que é social e histórica (PIRES DO RIO; GALVÃO, 1996, p.25). A abordagem geográfica pode trazer elementos de reflexão, sobretudo no que diz respeito às escalas e às estratégias de intervenção no espaço, ao processo de tomada de decisão e às imposições de atores institucionalizados. Desse modo, segundo Pires do Rio e Galvão (1996), a noção de gestão deve assumir hoje uma conotação mais ampla, onde a gestão ambiental é apresentada como palavra-chave para as estratégias de empresas e de atores públicos, tomando o tempo: ontem, hoje e amanhã como parâmetros.

Entendendo o espaço e sua dinâmica ambiental, emerge a questão da negociação de conflitos que deve considerar a efetivação de diferentes estratégias orientadas por diversos atores que produzem o espaço. Portanto, no processo de negociação, cada grupo representa certa visão do problema: grupos ecologistas, agentes imobiliários, empresas, órgãos da administração pública, etc. A negociação impõe-se, sob esta perceptiva, como condição para a tomada de decisão.

A necessidade de se reduzir os conflitos entre o crescimento da cidade e a conservação ambiental, garantindo a manutenção dos seus serviços ambientais, possui um ganho econômico, social e em qualidade de vida, indiscutíveis. A estabilização e preservação das encostas e áreas marginais dos cursos d'água, principalmente na bacia hidrográfica da Baía de Sepetiba, reduzem os riscos e, consequentemente, os gastos do poder público e as perdas sociais e até mesmo de vidas humanas em desastres. 
Repensar o desenvolvimento urbano é um caminho essencial para superar os desafios da sustentabilidade da ocupação e uso do solo em cidades como o Rio de Janeiro. Assim, como mencionado por Souza (1995), deve-se buscar uma mudança do modelo civilizatório envolvendo questões ligadas à materialidade das tecnologias, à organização espacial e à gestão das tecnologias, da natureza e dos espaços. Nesse ínterim, como proposta de ação, tem-se o Zoneamento Ecológico Econômico (ZEE) que se constitui em uma importante ferramenta capaz de auxiliar no planejamento e gestão do município do Rio de Janeiro, visto que os seus objetivos e suas diretrizes condizem com as necessidades da cidade e as definições previstas no Estatuto das Cidades.

Para um Novo Plano Diretor do Município se deve, igualmente, ser relacionado ao Plano de Bacia Hidrográfica, aos Planos de Manejo das Unidades de Conservação, ao Plano Municipal de Redução de Riscos e, sobretudo, estabelecer uma mesa de negociação com os diversos blocos socioterritoriais para o pacto de um projeto/planejamento de desenvolvimento.

\section{AGRADECIMENTOS}

Agradecemos a confecção dos mapas do artigo ao geógrafo Luiz Henrique Alves da Silva, doutorando do Programa de Pós-Graduação em Geografia, Universidade do Estado do Rio de Janeiro.

\section{REFERÊNCIAS}

ABREU, M. Evolução Urbana do Rio de Janeiro. Rio de Janeiro: Instituto Pereira Passos, 2006. Acselrad, H., (2004). As práticas espaciais e o campo dos conflitos espaciais. In: Acselrad, H. (Org.). Conflitos Ambientais no Brasil. Rio de Janeiro: Relume Dumará, pp. 13-35.

ACSELRAD, H.; HERCULANO, S.; PÁUDA, J. A. (Orgs.). Justiça Ambiental e Cidadania. Rio de Janeiro: Relume Dumará; Fundação Ford, 2004.

AGUIAR, A. P. D. "Modelagem de mudanças de uso e cobertura do solo na Amazônia: Questões Gerais". In: Introdução à Modelagem Dinâmica Espacial, organizado por Gilberto Câmara e Antônio Miguel Vieira Monteiro, apresentado no Simpósio Brasileiro de Sensoriamento Remoto, 2003.

ALMEIDA, H. R. A Geografia: o espaço e o tempo. In: Revista de Ciências Humanas. 2(3), p.: 7-15, 1982.

ARAÚJO, W. D. A Defesa Civil como Instrumento da Gestão Ambiental Urbana. Um Enfoque na Região da Bacia Hidrográfica da Baía de Sepetiba sob os Efeitos da Instalação de Novos Empreendimentos. COPPE/UFRJ, Especialização em Gestão de Bacias Hidrográficas, 2007.

ARONOFF, S., Geographic Information Systems: A Manegement Perspective. Ottawa: WDL Publications, 326 pp. 1989.

BACA, J. F. M. Dinâmica da Paisagem: métodos analíticos, modelos de classificação e simulação prognostica, sob a ótica geoecológica. Tese (Doutorado). Rio de Janeiro: UFRJ / Programa de pós-graduação em Geografia, 2002.

BARE, J. O choque de futuro: o Rio dos megaeventos. O social em questão, (16):1, pp.: 43-68, 2013.

BATISTA, M. A. N. (2009). Candidatura do rio de janeiro a patrimônio mundial: Categoria paisagem cultural. 8 o Seminário DOCOMOMO Brasil. Sumário de Trabalho. Rio de Janeiro, RJ,Brasil. 1-4 Set, 2009 Disponível em: <http://www.docomomo.org.br> Acesso em: 16 de junho de 2011.

BECKER, B. Geografia política e gestão do território no limiar do século XXI, Revista Brasileira de Geografia, nํ, Rio de Janeiro, 1991. 
BENEDETTI, A. C. P. Modelagem Dinâmica para Simulação de Mudanças na Cobertura Florestal das Serras do Sudeste e Campanha Meridional do Rio Grande do Sul. Tese de doutorado. Universidade Federal de Santa Maria. Centro de Ciências Rurais. Programa de Pós-Graduação Em Engenharia Florestal. Santa Maria, RS, Brasil, 2010.

BESER DE DEUS, L. A. B. Tempo em Sistemas de Informações Geográficas. Dissertação de Mestrado. IME, 2005.

BESER DE DEUS, L. A. Espaço e Tempo como Subsídios à Construção de Cenários de Uso e Cobertura da Terra para o Planejamento Ambiental na Amazônia: O Caso da Bacia do Rio Acre/ Leandro Andrei Beser de Deus - Rio de Janeiro: UFRJ/COPPE, 2013.

BRANDÃO, A.M.P.M. Clima urbano e enchentes no Rio de Janeiro. Cap2. In: GUERRA, A.J.T; CUNHA, S.B. (org). Impactos ambientais e urbanos no Brasil. Rio de Janeiro: Bertrand Brasil, pp. 47-109, 2001.

BRIASSOULIS, H. "Analysis of Land Use Change: Theoretical and Modeling Approaches". In: The Web Book of Regional Science, editor S. Loveridge, Regional Research Institute, West Virginia University, 2000. Disponível em: https://researchrepository.wvu.edu/cgi/viewcontent.cgi?article=1000\&context=rri-web-book. Acesso em: julho de 2020.

CÂMARA, G. Bertha Becker e o Futuro das Geotecnologias. Info GEO, Curitiba, v. 19, 01 jul. 2001.

COELHO, M. C. N. Impactos Ambientais em Áreas Urbanas - Teorias, Conceitos e Métodos de Pesquisa. In: GUERRA, A. J. T.; CUNHA, S. B. (orgs), Impactos Ambientais Urbanos no Brasil, p.: 19-45, 5a ed., Rio de Janeiro: Bertrand Brasil, 2009.

CONSTANTINOU. Dinâmica Intra-Urbana: Aleatoriedade e Emergência de Padrões Espaco-Temporais.Cadeias de Markov. Página V.

ELLIS, E. (Lead Author). "Land-use and land-cover change". Robert Pontius (Topic Editor). In: Encyclopedia of Earth. Eds. Cutler J. Cleveland (Washington, D.C.: Environmental Information coalition, National Council for Science and the Environment). [First published in the Encyclopedia of Earth April 18, 2010; Last revised Date May 7, 2012; Retrieved November 26, 2012 http://www.eoearth.org/article/Land-use_and_land-cover_change

FAO - Food and Agriculture Organization. A framework for land evaluation. Rome: Food and Agriculture Organization, 1976. 72 p. (FAO Soils Bulletin, n. 29). Disponível em: https://www.mpl.ird.fr/crea/taller-colombia/FAO/AGLL/pdfdocs/framele.pdf. Acesso em: julho de 2020.

FARIA, G. MEDEIROS, C. Um Banco de Dados Espaço-Temporal para o Desenvolvimento de Aplicações em Sistemas de Informação Geográficas. Dissertação de Mestrado. São Paulo: Unicamp, 1998.

Fundação Estadual de Engenharia do Meio Ambiente - FEEMA (2006). Complexo Lagunar de Jacarepaguá - Diagnóstico de Qualidade de Água, Período 2001 / 2005. Rio de Janeiro, RJ,Brasil.

GÓMEZ OREA, D. Ordenacion Territorial. 2ª̣ed. Madri: Mundi-Prensa, 2007.

GORALWALLA, I. A.; OZSU, M.T.; SZAFRON, D. An Object-Oriented Framework for Temporal Data Model. In: ETZION, O.; JAJODIA, S.; SRIPADA, S. Temporal Databases: research and practice. Berlin: Springer-Verlag, 1998. P.367-405.

GUEDES, M. J. Estudo e Pesquisa da Cartografia Histórica: Possibilidades e Desafios. Sumário. I Simposio Iberoamericano de Historia da Cartografia, 2006.

GUSMÃO, P. P. Apropriação e ordenamento territorial na zona costeira no estado do Rio de Janeiro. Grandes corporações ou as políticas públicas?. In: Revista Brasileira de Estudos Urbanos e Regionais, v. 12, N. 2. Novembro, 2010.

HERRERA, G. C. Naturaleza, sociedad e historia en América Latina, 1994.

IBGE - Instituto Brasileiro de Geografia e Estatística. Censo Demográfico de 2010. Rio de Janeiro: IBGE, 2010. Disponível em: < https://censo2010.ibge.gov.br/resultados.html> acesso em 10 de janeiro de 2015.

IBGE - Instituto Brasileiro de Geografia e Estatística. Manual técnico de uso da terra. 2 ed. Brasília: IBGE, 2006. 91p. (Manuais Técnicos em Geociências, n. 7).

INEA - Instituto Estadual do Ambiente. Boletim consolidado de qualidade das águas da Região Hidrográfica II - Gandu. Rio de Janeiro, RJ: Governo do Estado do Rio de Janeiro. Disponível em: < http://www.inea.rj.gov.br/wp-content/uploads/2020/01/Consolidado2019-RH-II.pdf> Acesso em 09 de julho de 2020.

IPP - Instituto Pereira Passos, Armazém de dados: Mapeamento de Cobertura e uso da Terra. Rio de Janeiro: IPP, 2010. Disponível em: < http://www.data.rio/datasets/cobertura-vegetal-e-uso-da-terra-2010> Acesso em 22 de janeiro de 2016.

KEMP, Z.; KOWALCZYK, A. Incorporating the Temporal Dimension in a GIS. In: Worboys, M. F.(org.) Innovations of GIS. Londres: Taylor \& Francis, 1994.

KILIAN, R. Cenarização: a ferramenta essencial para uma estratégia efetiva / Rudibert Kilian Júnior. - 2009. 331 p.; il. Dissertação (Mestrado em História Comparada) - Universidade Federal do Rio de Janeiro, Rio de Janeiro, 2009. 
LANGRAN, G. Time in Geographic Information Systems. DC: Taylor \& Francis, 1993. 189p.

MACHADO DA SILVA, L. A. "Violência urbana", segurança pública e favelas - o caso do Rio de Janeiro atual. Caderno CRH, Salvador, v. 23, n. 59, p. 283-300, maio/ago. 2010.

MARKOV, A. A. Extension of the limit theorems of probability theory to a sum of variables connected in a chain. Reimpresso no Apêndice B de: R. Howard. Dynamic Probabilistic Systems, volume 1: Markov Chains. John Wiley and Sons, 1971.

MEDEIROS, C. B.; BOTELHO, M. A. Tratamento do Tempo em SIG. GIS Brasil 96, 1996. p. 534-544.

MENDONÇA, F. A. Riscos, Vulnerabilidades e Resiliência Socioambientais Urbanas: Inovações na Análise Geográfica. Revista da ANPEGE. V.07, n.01, número especial, p. 111-118. Outubro de 2011.

MENEZES, P. M. L. et al.Cartografia Histórica - Revisão de Conceitos e a Análise Geográfica. In: Anais do XXII Congresso Brasileiro de Cartografia, 2005.

NUNES, L. H. Mudanças Climáticas, Extremos Atmosféricos e Padrões de Risco a Desastres Hidrometeorológicos. In Populações e Mudanças Climáticas: Dimensões Humanas das Mudanças Ambientais Globais. Hogan, D. J. \& Marandola Jr, E. (organizadores), Campinas: NEPO/Unicamp, p. 53-74. 2009.

OLIVEIRA, R. Ações do homem e o meio ambiente. Entrevista publicada pela Ed. PUC-Rio em 2006.

OLIVEIRA, S. A releitura dos critérios de justiça na região dos Lagos do Rio de Janeiro. In: Conflitos Ambientais no Brasil. Acselrad, Henri (Org.) Rio de Janeiro: Relume Dumará: Fundação Heinrich Böll, p. 95-130. 2004.

OSCAR JÙNIOR, A. C. S. Geografia e panarquia: noções teóricas para evolução do conhecimento a respeito de um sistema territorial. Revista GEOSUL, 31. 61, p.: 155-180, 2016.

OSCAR JÚNIOR, A. C. S. Ordenamento Territorial e riscos ambientais de natureza atmosférica no município de Duque de Caxias (RJ). Dissertação de Mestrado. Rio de Janeiro: PPGG da UFRJ. 2014.

PEDROSA, B. M.; CÂMARA, G. Modelagem Dinâmica e Geoprocessamento. In: Análise Espacial de Dados Geográficos. Druck, S.; Carvalho, M.S.; Câmara, G.; Monteiro, A.V.M (eds) Brasília, EMBRAPA, 2004

PEUQUET, D. An event-based spatiotemporal data model (ESTDM) for temporal analysis of geographical data. International Journal of Geographical Information Systems, 9(1), p.7-24, 1995.

PIRES DO RIO, G. A.; GALVÃO, M. C. C., (1996). Gestão Ambiental: Apontamentos para uma Reflexão. Anuário do Instituto de Geociências, vol. 16, Rio de Janeiro, UFRJ, p.15-44, 1996.

ROCHA, C. H. B. Geoprocessamento: Tecnologia Transdisciplinar. Juiz de Fora - MG: Ed. do Autor, 2000. 220 p.

ROCHA, L. V. Geo-Frame-T: Um FRAMEWORK Conceitual Temporal para Aplicações de sistemas de Informação Geográfica. Dissertação de Mestrado. Porto Alegre: PPGC da UFRGS, 2001.

SANTOS, M. A Natureza do Espaço: Técnica e Tempo, Razão e Emoção. São Paulo: Editora da Universidade de São Paulo, 2008.

SANTOS, R. F. S. Planejamento Ambiental: teoria e prática. São Paulo: Oficina de Textos, 2004.

SELLIS, T. et al. Research Network for Spatiotemporal Database Systems. SIGMOD Records, New York, v.28, n.3, 1999.

SMAC - Secretaria Municipal de Meio Ambiente (SMAC). (2005). SMAC, 10 anos. Rio de Janeiro, RJ: Prefeitura da Cidade do Rio de Janeiro.

SOARES-FILHO, B. S.; RODRIGUES, H. O.; CERQUEIRA, G. C.; COSTA, W. L. S.; ARAÚJO, W. L.; OLIVEIRA, L. B. R. Software Dinamica EGO: Environment for Geoprocessing Objects. CSR/UFMG. Versão 1.2.1. 2005.

SOUZA, M. L. "A crescente fragmentação do tecido sócio-político-espacial das metrópoles do Rio de Janeiro e de São Paulo: Um desafio para a agenda do Desenvolvimento Urbano Sustentável". In: Exclusão social, fragmentação do tecido sócio-político-espacial da cidade e'ingovernabilidade urbana'. Ensaio a propósito do desafio de um 'desenvolvimento urbano sustentável' nas cidades brasileiras. $4^{\circ}$ Simpósio Nacional de Geografia Urbana. Fortaleza, outubro. 1995.

TURNER, B. L. II; B. L. MEYER.. Global Land Use and Land Cover Change: An Overview. In: MEYER, W. B.; TURNER B. L. II (org.) Changes in Land Use and Land Cover: A Global Perspective, p.: 3-10. Cambridge: Cambridge University Press, 1994.

VEYRET, I. Os Riscos: o homem como agressor e vítima do meio ambiente. São Paulo: Contexto, 2007. 